\title{
Nanoseconds Switching for High Voltage Circuit Using Avalanche Transistors
}

\author{
Abd Rahman Tamuri (Corresponding author) \\ Laser Technology Laboratory \\ Physics Department, Faculty of Science \\ Universiti Teknologi Malaysia, 81310, Skudai \\ Johor Bharu, Johor, Malaysia
}

Tel: 60-7-553-4096 E-mail: rahman_t@hotmail.com

\author{
Noriah Bidin \\ Head of Physics Department, Faculty of Science \\ Universiti Teknologi Malaysia, 81310, Skudai \\ Johor Bharu, Johor, Malaysia
}

Tel: 60-7-553-4009 E-mail: noriah@utm.my

Yaacob Mad Daud

Physics Department, Faculty of Science

Universiti Teknologi Malaysia, 81310, Skudai

Johor Bharu, Johor, Malaysia

Tel: 60-7-553-4096 E-mail: ymd@dfiz2.fs.utm.my

\begin{abstract}
The avalanche transistor is suitable for switching high voltage in kilovolts region. In this paper, a simple switching circuit consists of avalanche transistor is demonstrated. Sixteen of ZTX 415 avalanche transistors were used to switch a high voltage circuit up to $4.5 \mathrm{kV}$. A PIC16F84 microcontroller was utilized as control unit to generate input trigger. The result shows that the developed circuit was able to switch applied voltage up-to $4.5 \mathrm{kV}$ with an average falling time is $2.89 \mathrm{~ns}$.
\end{abstract}

Keywords: Avalanche transistor, High voltage, Microcontroller

\section{Introduction}

The operation of an electro-optically Q-switched laser requires fast switching of voltages in the multi-kilovolt regime (Chadderton, 19961; W. Koechner, 2006). Nanosecond scale high-voltage pulse generator or driver requires extremely high switching speeds. It is also capable of producing current outputs far in excess of that obtained from conventional circuits. In particular, the half-voltage of $\mathrm{KD}^{*} \mathrm{P}$ crystal Pockels cell is about $5.9 \mathrm{kV}$ and needs the voltage to switch to zero within few nanoseconds in order to produce a short laser pulse (W. Koechner, 2006).

The common switching techniques include the use of MOSFETs (Alton and Sundararaja, 2004), SCRs and avalanche transistors (W. G Maguson, 1962; Molina et al, 2002, Jankee and Navathe, 2006, Lui Jinyuan et al, 1998). Each switch has its advantages and applications. The avalanche transistor mode is ideally suitable for this operation and has wide applications in laser Q-switching (Chadderton, 1996; E. S. Fulkerson \& R. Box; C. Alton and R. Sundararajan, 2004 ; E. S. Fulkerson et al, 1997; ZTX 415 Datasheet,). Avalanche transistors are normally connected in series and operated close to their avalanche breakdown voltage. When triggered, all the transistors are switched on, and the transient pulse 
switching appears on Pockels cell. This effect changes the polarization state of Pockels cell which blocks or deflects light from passing through the crystal. The speed of switching and voltage applied across the crystals will determine the pulse duration of the laser output (W. Koechner, 2006)

In this paper, a simple circuit of avalanche transistors was developed to switch in the kilovolt regime. A series avalanche transistor was designed to switch up to $4.5 \mathrm{kV}$ within few nanoseconds.

\section{High Voltage Switching Circuit Design}

The circuit shown in Figure (1) was designed to drive a Pockels Cell for a Q-switched Nd:YAG laser within a $0-4.5$ $\mathrm{kV}$ DC voltage. This circuit includes three main components, high voltage power supply, trigger unit and control unit. The high voltage power supply provides DC voltage to Pockels Cell in the range of $4.5 \mathrm{kV}$. The trigger unit was used to chop the DC voltage to zero when initiated by control unit. The trigger unit circuit consists of a series of avalanche transistors such as illustrated in Figure (1).

The high voltage power supply is connected to trigger unit through two, series $1 \mathrm{MOhm}$ resistors. The avalanche

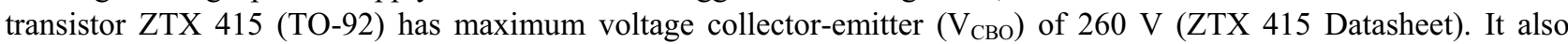
possess high peak collector current of about $60 \mathrm{~A}$ with a pulse width shorter than $20 \mathrm{~ns}$. Each avalanche transistor base is directly connected to emitter except the last one $\left(\mathrm{Q}_{1}\right)$. Transistor $\mathrm{Q}_{1}$ is triggered via a control unit connected through a $100 \mathrm{Ohm}$ resistor.

Initially transistor $\mathrm{Q}_{1}$ is triggered, through the collector near the ground potential; resulting in about $300 \mathrm{~V}$ between the collector and emitter voltage across the second transistor $\mathrm{Q}_{2}$. This second transistor, $\mathrm{Q}_{2}$ experiences a nondestructive avalanche breakdown due to this over voltage. Consequently each transistor in turn experienced an even greater overvoltage due to a faster rise time and a shorter delay. Finally, transistor $\mathrm{Q}_{16}$ is turn to experience the high voltages, fast fall time.

The control unit was designed to operate in two modes, single and repetitive mode. For calibration purposes, the control unit was set to operate in a single mode. A single push button connected to PIC16F84A microcontroller was employed to perform this task. When, the push button is pressed, the microcontroller produced a single $10 \mu$ s pulse. This pulse was then triggered a BC547 transistor. The output of this transistor was used to trigger the first avalanche transistor.

\section{Methodology}

In this experiment a developed avalanche transistor circuit was calibrated. A Tektronix TDS 3054B digital oscilloscope with a bandwidth of $500 \mathrm{MHz}$ and sampling rate of $5 \mathrm{GS} / \mathrm{s}$ was used to display and to measure the electronic signal. A high-voltage probe (Tektronix P6015A) with the maximum voltage of $20 \mathrm{kV} \mathrm{DC}$ or $40 \mathrm{kV}$ for pulse was utilized to measure the high voltage supplied across the circuit. The flow chart of the measurement is shown as in Figure (2). The variable high voltage DC power supply in the range of 0 to $4.5 \mathrm{kV}$ was connected directly to the developed circuit. For safety reason as well as to eliminate noise and to avoid electric shock the experimental setup was arranged properly. When the high speed switching occurs in kilovolt regime, electromagnetic induction (EMI) is expected to occur. This effect was avoided by designing the circuit on one layer of printed circuit board (PCB) and all the components were soldered and sealed properly. All the components and circuit are kept in isolated plastic case such illustrated as in Figure (3). The parameters such as the voltage switching, falling time and pulse duration were measured using the high voltage probe and oscilloscope.

\section{Result and Discussion}

The typical high voltage switching signal measured by Tektronix oscilloscope is shown in Figure (4). The input signal from control unit via PIC16F84A generated 10 microseconds pulse (bottom signal in Figure (4)). After the high voltage supply is switched to ground, the voltage is raised again within 90 microseconds (upper signal of Fig. 4). In this experiment, the maximum supply of DC voltage was $4.5 \mathrm{kV}$. Figure 5 shows the switching signal at $4.36 \mathrm{kV}$ with a time scale of $4 \mathrm{~ns}$ time/division. The voltage reached its ground level within 3.04 nanoseconds. The falling time of high voltage switching was measured using Tektronix high voltage probe and Tektronix oscilloscope $5 \mathrm{GHz}$ sampling rate.

The collected data of falling time were recorded. Figure (6) shows a graph of the switching falling time versus applied voltage. A nonlinear graph is obtained with the average of switching falling time of $2.89 \mathrm{~ns}$. The developed circuit also produced negative voltage and small ripple in nanoseconds scale. The maximum negative voltages were measured and represented in Figure (7). The negative voltages were in linear relationship with the applied voltage. In certain case, this voltage could increase the Q-switching efficiency due to the full retardation of laser beam. For commercial purpose, the circuit should produce sharp pulse with small ripple. The high voltage supplied to the avalanche transistor caused it to change its shape due to the piezoelectric effect. This effect could be eliminated by adding RC component in the circuit. Furthermore, by using PIC microcontroller, the pulse duration of trigger signal easily adjusted and controlled. In addition, the developed circuit also able to operate in high repetition rate mode up to $1 \mathrm{MHz}$. 


\section{Conclusion}

A simple high-voltage pulse switching circuit using avalanche transistor and PIC16F84A microcontroller was successfully developed and characterized. The maximum operation voltage was $4.5 \mathrm{kV}$ with average falling time of switching pulse is $2.89 \mathrm{~ns}$.

\section{Acknowledgment}

The authors would like to express their thanks to Universiti Teknologi Malaysia and the Government of Malaysia for the financial support for this project.

\section{References}

C. Alton \& R. Sundararajan. (2004). Simple MOSFET-Based High-Voltage Nanosecond Pulse Circuit. IEEE Transactions on Plasma Science, Vol. 32, No. 5, Oct 2004.

E. S. Fulkerson \& R. Box. Design of reliable high voltage avalanche transistor pulsers. Lawrence Livermore National Laboratory.

E. S. Fulkerson, D. C. Norman \& R. Booth. (1997). Driving Pockels Cell Using Avalanche Transistor Pulsers. 11 ${ }^{\text {th }}$ IEEE International Pulse Power Conference, Baltimore, Maryland.

L. L. Molina, A. Mar, F. J. Zutavern, G. M. Loubriel \& M. W. O’Malley. (2002). Sub-nanosecond avalanche transistor drivers for low impedance pulsed power applications. IEEE, pp 178-181

Lui Jinyuan, Shan Bing \& Chang Zenghu. (1998). High Voltage fast ramp pulse generation using avalanche transistor. Review of Scientific Instruments, Vol. 69, No. 8, 3066-3067

N. Chadderton. (1996). The ZTX 415 Avalanche Mode Transistor: An Introduction to Characteristics, Performance and Application. Application Note, Issue 2

(1995). NPN Silicon planar avalanche transistor ZTX 415: Datasheet, Issue 4 - Nov 1995.

U. Jankee \& C. P. Navathe. (2006). A fast high-voltage pulse generator with variable amplitude and duration. Design Note, Meas. Sci. Technol., 17, N25-N28.

W. Koechner. (2006). Solid State Laser Engineering. 6th Edition, United State of America, Springer Science-Business Media. pp 514-516.

W.G. Magnuson. (1962). Variable-width pulse generation using avalanche transistor. IEEE Transactions on Instrumentation and Measurement, Sep, pp 56-64.

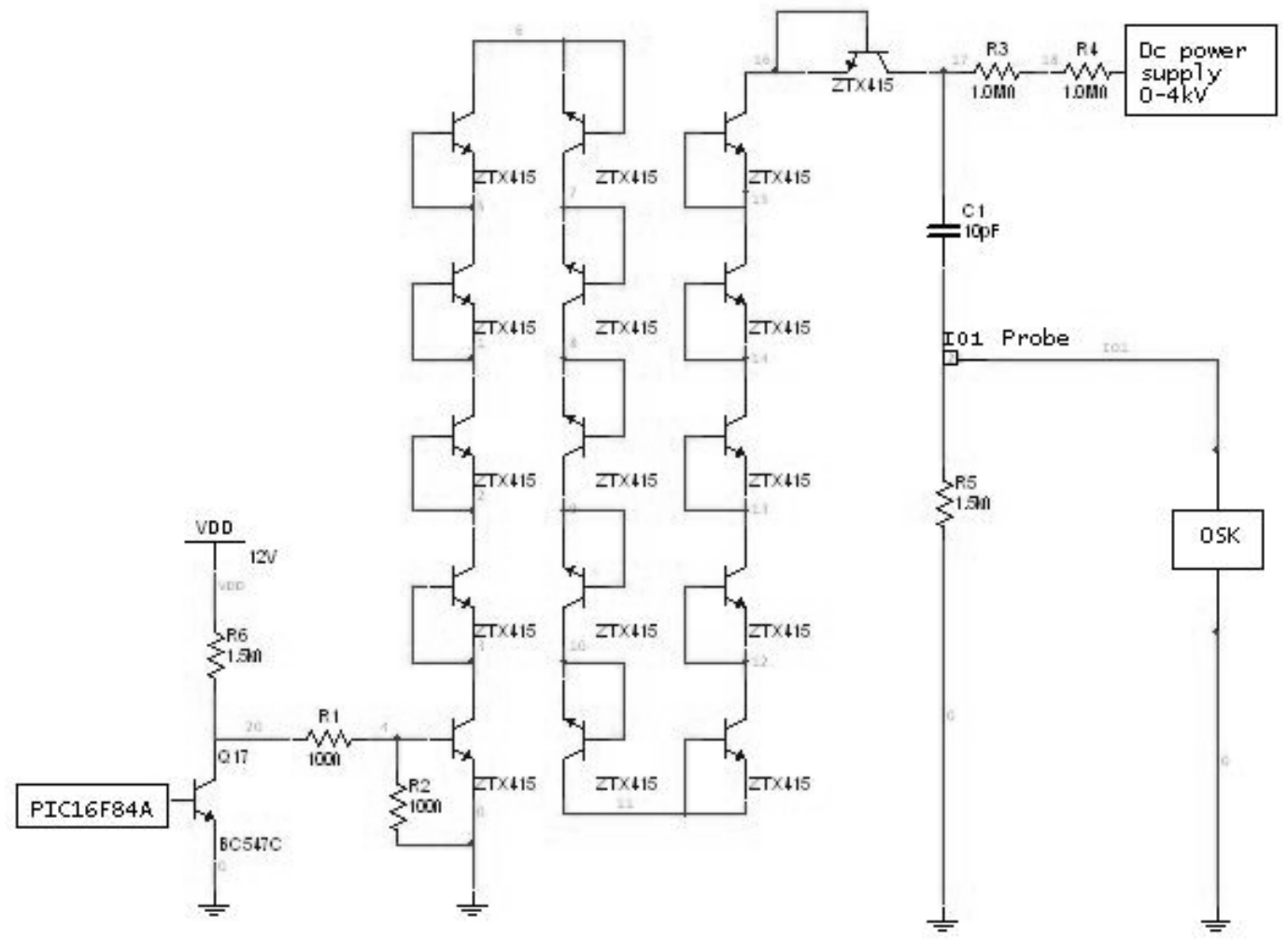

Figure 1. Schematic diagram of high voltage avalanche transistor trigger circuit 


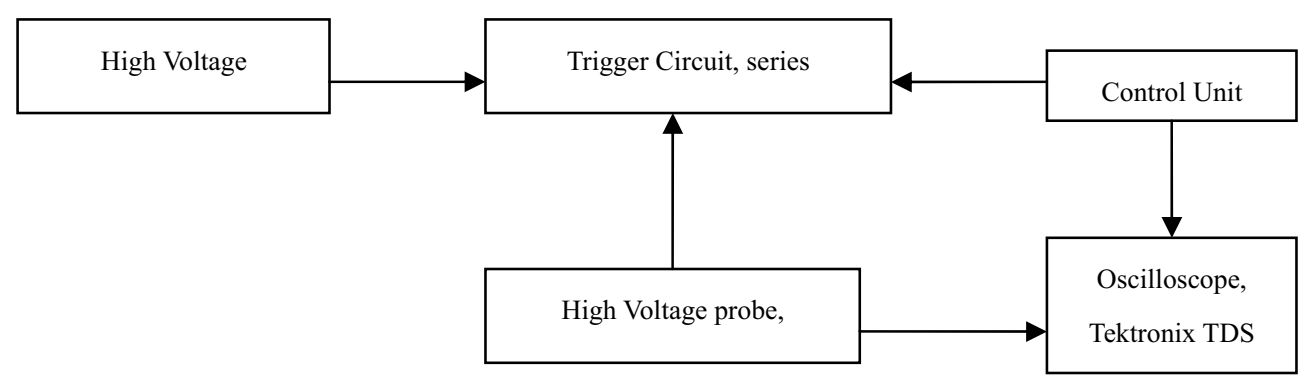

Figure 2. The flow chart of experimental work

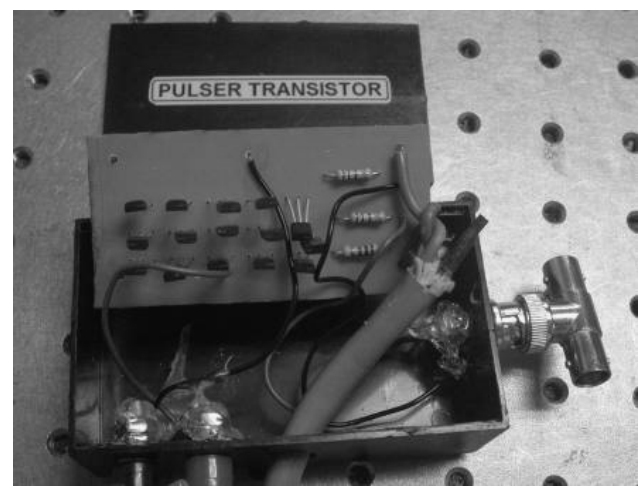

Figure 3. The developed avalanche transistor circuit on PCB in the plastic case

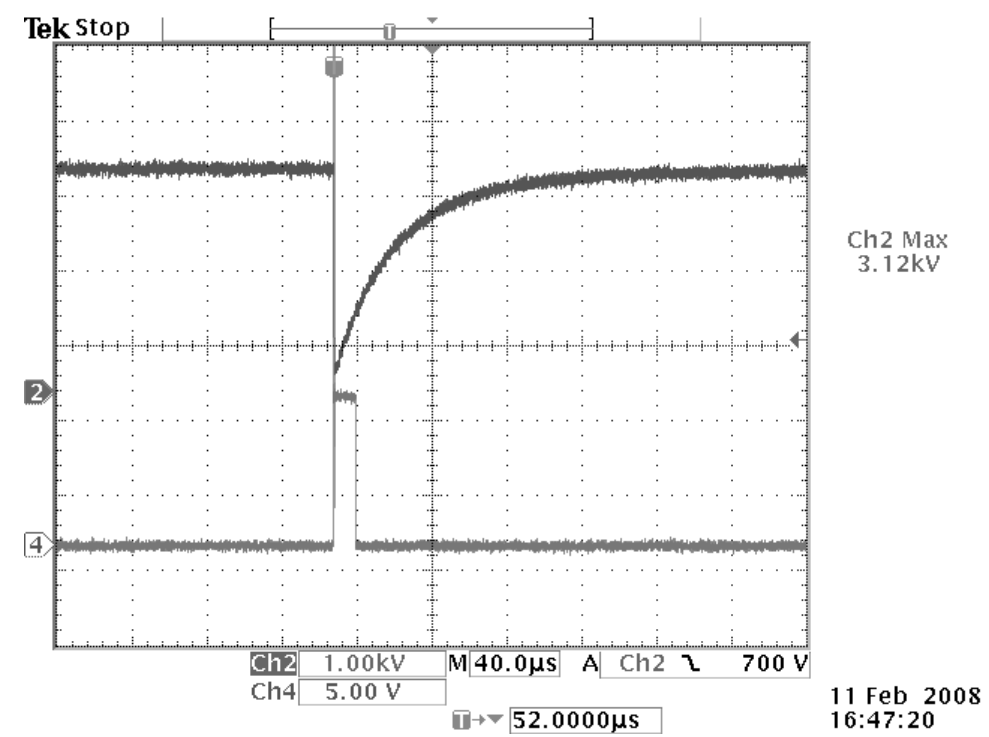

Figure 4. High voltage switching signal 


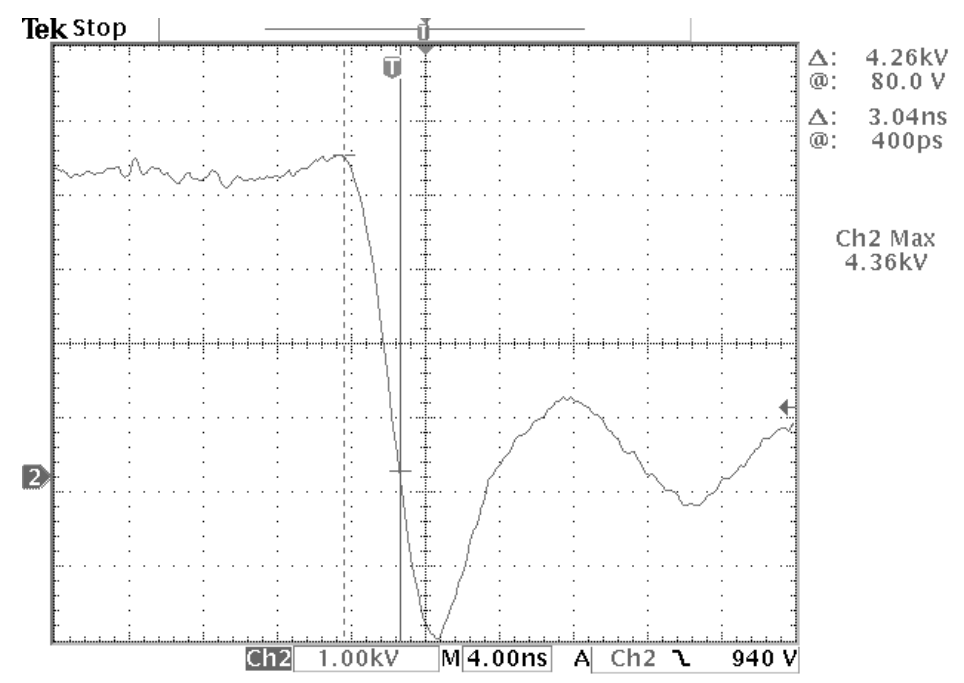

Figure 5. Typical result of nanosecond pulse

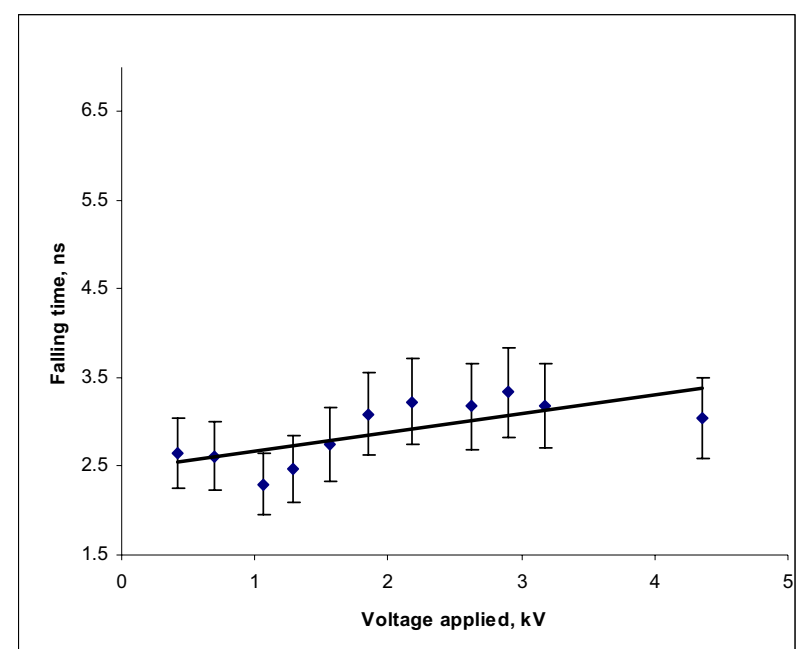

Figure 6. The graph of falling time versus applied voltage.

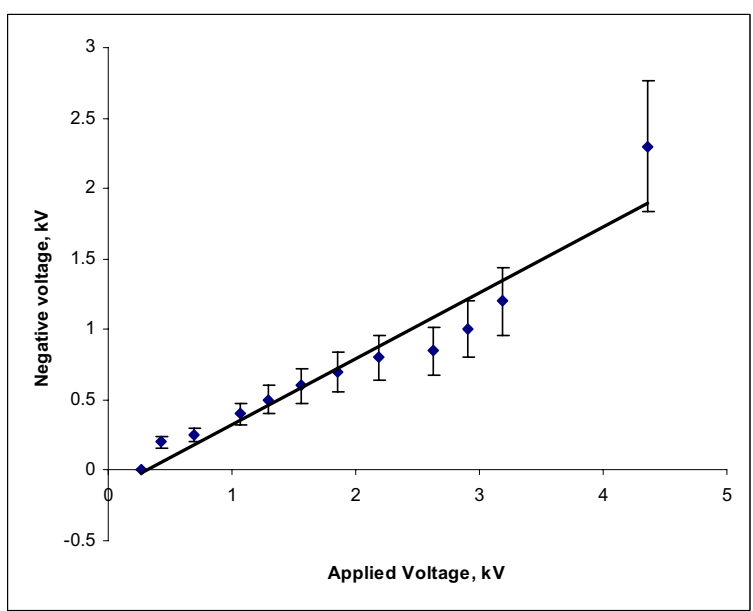

Figure 7. Negative voltage of high voltage switching 